\title{
EFEITOS DO ALUMÍNIO, NITRATO E AMÔNIO SOBRE A COMPOSIÇÃO DE METABÓLITOS NITROGENADOS E DE CARBOIDRATOS EM STYLOSANTHES GUIANENSIS E S. MACROCEPHALA ${ }^{1}$
}

\author{
JOSÉ AUGUSTO TEIXEIRA DO AMARAL ${ }^{2}$, ANTONIO TEIXEIRA CORDEIRO ${ }^{3}$ e ALEMAR BRAGA RENA ${ }^{4}$
}

\begin{abstract}
RESUMO - Estudaram-se, em condições controladas, os efeitos da interação de alumínio, nitrato e amônio, em solução nutritiva, sobre os teores de compostos nitrogenados e de açúcares em Stylosanthes guianensis e $S$. macrocephala, sensível e tolerante, respectivamente, tanto ao Al quanto ao amônio. A nutrição amoniacal causou o aparecimento de sintomas de toxidez de amônio apenas em $S$. guianensis. A fonte amoniacal aumentou as concentrações de $\mathrm{N}$-solúvel, $\mathrm{N}$-amoniacal e $\mathrm{N}$-aminoácidos principalmente na parte aérea de $S$. guianensis e no sistema radicular de $S$. macrocephala, ao passo que os teores de açúcares solúveis totais aumentaram na parte aérea de $S$. guianensis e decresceram no sistema radicular das duas espécies. O Al atenuou parcialmente a toxidez de amônio em $S$. guianensis. Quando o $\mathrm{N}$ foi suprido pela fonte nítrica, a adição do $\mathrm{Al}$ à solução nutritiva causou o aparecimento de sintomas de toxidez apenas em $S$. guianensis. Já em $S$. macrocephala, nessas condições, ocorreram aumentos nos teores de $\mathrm{N}$-total, $\mathrm{N}$-insolúvel, N-solúvel, N-nítrico e $\mathrm{N}$-aminoácidos na parte aérea e nas raízes, seguidos de decréscimos nos teores de açúcares solúveis totais e redutores nas raízes.
\end{abstract}

Termos para indexação: toxidez de Al, toxidez de amônio.

\section{EFFECTS OF ALUMINUM, NITRATE AND AMMONIUM ON THE METABOLIC NITROGENED COMPOSITION AND OF CARBOIDRATES IN STYLOSANTHES GUIANENSIS AND S. MACROCEPHALA}

\begin{abstract}
The effects of aluminum, nitrate and ammonium interaction, in nutritive solution, on the concentration of nitrogened compound, and of sugar in Stylosanthes guianensis and S. macrocephala, sensitive and tolerant, respectively, both to aluminum and to ammonium were studied under controlled conditions. The ammonium nutrition caused the appearance of toxicity symptoms of ammonium only in the S. guianensis. The ammonium source increased the concentrations of N-soluble, N-ammonium and N-amino acid mainly in the aerial part of the $S$. guianensis and in the root system of the $S$. macrocephala, while the total soluble sugar concentration increased in the aerial part of the $S$. guianensis and decreased in the root system of both species. The aluminum relieved partially the ammonium toxicity in the S. guianensis. When the nitrogen was supplied by the nitric source, the addition of the aluminum to the nutritive solution caused the appearance of symptoms of toxicity only in the $S$. guianensis. In the $S$. macrocephala, under the same conditions, an increase of total $\mathrm{N}$, insoluble $\mathrm{N}$, soluble $\mathrm{N}$, nitric $\mathrm{N}$ and amino acid $\mathrm{N}$ in the aerial part and in the roots ocurred, followed by a decrease in the total soluble sugar concentration and sugar reductor in the roots.
\end{abstract}

Index terms: aluminum toxicity, ammonium toxicity.

\section{INTRODUÇÃO}

${ }^{1}$ Aceito para publicação em 19 de julho de 1999.

${ }^{2}$ Eng. Agrôn., D.Sc., Prof. Adj., Dep. de Fitotecnia, Universidade Federal do Espírito Santo, Caixa Postal 16, CEP 29500-000 Alegre, ES. E-mail: augusto@npd.ufes.br

${ }^{3}$ Eng. Agrôn., D.Sc., Dep. de Biologia Vegetal, Universidade Federal de Viçosa (UFV), CEP 36571-000 Viçosa, MG.

${ }^{4}$ Eng. Agrôn., Ph.D., Prof. Titular, Dep. de Biologia Vegetal, UFV.
Estudos sobre a toxidez de Al demonstram a existência de muitos efeitos nocivos desse cátion sobre o metabolismo das plantas (Foy et al., 1978; Marschner, 1986; Kochian, 1995). Essa diversidade de efeitos, associada à falta de um radioisótopo adequado do $\mathrm{Al}$, tem dificultado a elucidação do 
mecanismo fisiológico que confere tolerância diferencial das plantas a esse elemento (Foy, 1974).

Ainda que as causas fisiológicas da tolerância ao Al permaneçam obscuras, há algumas informações que sugerem uma possível inter-relação entre a toxidez de Al e o metabolismo do N. Em S. humilis, Mosquim (1978) observou aumentos nos teores de aminoácidos livres totais e de proteínas com o incremento da concentração de Al no meio de cultivo. Kotze et al. (1977) sugeriram que a toxidez de Al estaria relacionada com o metabolismo do nitrato. Segundo Cordeiro (1981), a influência do Al sobre o crescimento de espécies do gênero Stylosanthes depende da fonte de $\mathrm{N}$ utilizada, visto que incrementos nos níveis de Al na presença do nitrato reduziram até o crescimento da espécie tolerante, efeitos nocivos que não se manifestaram quando a fonte de $\mathrm{N}$ foi o amônio. Essa idéia foi ampliada por Gonçalves (1983), que, baseado em dados de absorção de $\mathrm{N}$ e de atividade enzimática, sugeriu que a tolerância diferencial ao Al estaria relacionada com a absorção, translocação e assimilação do nitrato e do amônio.

É possível que o mecanismo fisiológico da tolerância ao Al esteja associado com a tolerância ao amônio. Isto porque as espécies tolerantes ao $\mathrm{Al}$ desenvolveram algum mecanismo de adaptação às condições de solos ácidos, onde o amônio é a forma de $\mathrm{N}$ predominante disponível para as plantas (Gigon \& Rorison, 1972). Dessa forma, muitas espécies adaptadas a solos ácidos, e, portanto, tolerantes ao $\mathrm{Al}$, podem tolerar níveis de amônio que normalmente são tóxicos para espécies não-adaptadas; em alguns casos, o amônio é até essencial ao crescimento e desenvolvimento normais (Foy et al., 1978). Para Vaccinium macrocarpon, espécie adaptada a solos ácidos (Medappa \& Dana, 1970), o amônio é essencial ao crescimento (Greidanus et al., 1972), coincidindo com a falta de atividade da redutase do nitrato na parte aérea (Dirr, 1974). No entanto, a falta de atividade dessa enzima em espécies calcífugas parece não ser característica universal (Gonçalves, 1983).

Este trabalho teve por objetivo determinar, em solução nutritiva, os efeitos da interação $\mathrm{Al}$, nitrato e amônio sobre os teores de compostos nitrogenados e de açúcares, em duas espécies de Stylosanthes, sendo uma tolerante e outra sensível, tanto ao Al quanto ao amônio.

\section{MATERIAL E MÉTODOS}

Os experimentos foram conduzidos em uma sala de crescimento com temperatura de $28 \pm 2^{\circ} \mathrm{C}$, umidade relativa do ar em torno de $55 \%$, fotoperíodo de 12 horas e intensidade luminosa de $2,0 \mathrm{~mW} / \mathrm{cm}^{2}$, aproximadamente, fornecida por lâmpadas fluorescentes tipo luz do dia.

Sementes de Stylosanthes guianensis (Aubl.) sw. e de S. macrocephala M. B. Ferr. \& Souza Costa, espécies sensível e tolerante, tanto ao Al quanto ao amônio, respectivamente, foram escarificadas com lixa de madeira, esterilizadas superficialmente com hipoclorito de sódio a $0,5 \%$, durante 10 minutos, e lavadas repetidas vezes com água destilada. Posteriormente, foram colocadas para germinar em placas de Petri que continham solução de cloreto de $\mathrm{Ca}$ (4 ppm). Transcorridas 36 horas, as sementes germinadas foram transferidas para caixas de plástico com vermiculita esterilizada, umedecida, por capilaridade, com solução de cloreto de $\mathrm{Ca}(40 \mathrm{ppm})$ e micronutrientes, nas concentrações descritas a seguir. Decorridas 36 horas, selecionaram-se as plantas mais uniformes, que foram transferidas para frascos de plástico recobertos externamente de tinta-alumínio, com 1,6 litro de solução nutritiva de crescimento, com a seguinte composição, em ppm: $\mathrm{N}=32 ; \mathrm{P}=0,4 ; \mathrm{K}=70 ; \mathrm{Ca}=40$; $\mathrm{Mg}=12 ; \mathrm{S}=54,4 ; \mathrm{Fe}=2,2 ; \mathrm{B}=0,5 ; \mathrm{Mn}=0,38 ;$ $\mathrm{Zn}=0,05 ; \mathrm{Cu}=0,02 ; \mathrm{Mo}=0,02 ; \mathrm{Na}=23$ e Cl$=22,7 . \mathrm{O}$ $\mathrm{N}$ foi fornecido na razão de $\mathrm{N}-\mathrm{NO}_{3}^{-}$e $\mathrm{N}-\mathrm{NH}_{4}^{+}$de $7: 1$. Durante o período de crescimento, que se prolongou por dez dias, as trocas das soluções nutritivas foram realizadas no quarto, sexto e oitavo dias após a transferência das plantas para os frascos definitivos. Vinte e quatro horas antes de submeter as plantas aos tratamentos, a solução nutritiva foi trocada por outra, que continha apenas $\mathrm{Ca} \mathrm{e}$ micronutrientes, nas concentrações acima descritas.

Os tratamentos foram iniciados pela modificação da solução nutritiva de crescimento, pela adição de nitrato ou amônio, na presença ou na ausência do Al. O delineamento experimental foi inteiramente casualizado, no esquema fatorial $2 \times 2 \times 2$ : duas espécies, dois níveis de $\mathrm{Al}\left(0\right.$ e 9 ppm), fornecido na forma de $\mathrm{Al}_{2}\left(\mathrm{SO}_{4}\right)_{3} \cdot 18 \mathrm{H}_{2} \mathrm{O}$ e duas fontes de $\mathrm{N}$ (nítrica e amoniacal), com três repetições, sendo cada repetição constituída por 20 plantas. Para que se obtivesse $100 \%$ de $\mathrm{N}$ na forma nítrica e $100 \%$ de $\mathrm{N}$ na forma amoniacal, o nível de $\mathrm{S}$ foi de 44,2 e 115,8 , o de $\mathrm{Na}$ de 21,3 e 18,4 e o de $\mathrm{Cl}$ de 22,7 e 21,3 ppm, respectivamente. As trocas das soluções nutritivas, nessa etapa, foram realizadas diariamente. Em todas as fases do experimento o $\mathrm{pH}$ das soluções foi ajustado, diariamente, para 4,00 $\pm 0,02$, com $\mathrm{H}_{2} \mathrm{SO}_{4}$ e/ou $\mathrm{NaOH} 0,1 \mathrm{~N}$. 
Transcorridos 12 dias, contados do início dos tratamentos, procedeu-se à coleta do material vegetal, seccionando-se as plantas de cada repetição, na altura do coleto, na parte aérea e no sistema radicular. As raízes foram lavadas com água destilada, e enxugadas com papel absorvente. Em seguida, dez plantas de cada repetição foram pesadas, acondicionadas em sacos de papel, e transferidas para estufa de circulação forçada, a $80^{\circ} \mathrm{C}$, por 48 horas. Posteriormente, essas amostras foram novamente pesadas e pulverizadas em moinho Willey, com peneira de 40 mesh, e armazenadas em frascos de vidro, para as determinações posteriores do N-total e N-nítrico. As plantas remanescentes foram, imediatamente após a determinação do peso da matéria fresca, rapidamente fragmentadas, por meio de tesoura, e imersas em etanol fervente a $80 \%$, e armazenadas em congelador, a $-10^{\circ} \mathrm{C}$, para posterior extração do $\mathrm{N}$ solúvel e dos carboidratos solúveis das amostras, utilizando-se a metodologia descrita por Wang \& Waygood (1962), com algumas modificações. Inicialmente, o material vegetal, imerso em etanol a $80 \%$, foi triturado em gral de porcelana, até a obtenção de uma polpa fina, com a adição de areia lavada finamente moída. Seguiu-se a transferência quantitativa do material homogeneizado para tubos de centrífuga de $50 \mathrm{~mL}$, para posterior centrifugação a $30.000 \mathrm{~g}$ a $20^{\circ} \mathrm{C}$, por 5 minutos. Decantado o sobrenadante, submeteu-se o resíduo a três extrações sucessivas com $20 \mathrm{~mL}$ e a duas extrações com $10 \mathrm{~mL}$ de etanol fervente a $80 \%$. Feitas as centrifugações, os extratos etanólicos de cada repetição foram combinados, seguindo-se a eliminação do etanol em evaporador rotativo a vácuo, a $45^{\circ} \mathrm{C}$. O extrato aquoso assim obtido foi submetido a quatro extrações consecutivas, com igual volume de clorofórmio, em funil de separação, para remoção dos pigmentos e dos lipídios. Feito isso, a fase aquosa resultante foi evaporada a vácuo, a $45^{\circ} \mathrm{C}$, até a secura, e o resíduo foi dissolvido em $8 \mathrm{~mL}$ de 1-4 ditioeritritol $2,5 \mathrm{mM}$, e filtrado em papel de filtro $\mathrm{W}$ no 1 , constituindo o extrato aquoso I, o qual foi armazenado em congelador, a $-10^{\circ} \mathrm{C}$, para posterior determinação dos teores de N-solúvel total e de carboidratos solúveis.

Para a preparação dos extratos a serem utilizados na avaliação dos teores de $\mathrm{N}$-aminoácidos e de $\mathrm{N}$-amoniacal, colocou-se uma alíquota de $1 \mathrm{~mL}$ do extrato aquoso I de cada repetição em tubos de centrífuga, precipitando-se as proteínas com igual volume de ácido tricloroacético (TCA) a 10\% (Sodek \& Wilson, 1971). Após 12 horas de repouso, a $4^{0} \mathrm{C}$, os extratos foram centrifugados a $48.000 \mathrm{~g}$ a $4^{0} \mathrm{C}$, por 5 minutos, seguindo-se duas lavagens sucessivas do precipitado com $2 \mathrm{~mL}$ de TCA a $5 \%$. Os sobrenadantes das três repetições de cada tratamento foram combinados, e, após transferência quantitativa para tubos de vidro de $50 \mathrm{~mL}$, com tampa rosqueada, o TCA foi removido com quatro extrações consecutivas com igual volume de éter etílico, com o auxílio de uma trompa de vácuo. A seguir, evaporou-se a fase aquosa a vácuo, a $45^{\circ} \mathrm{C}$, até a secura, e dissolveu-se o resíduo em $5 \mathrm{~mL}$ de água destilada, obtendo-se assim o extrato aquoso II. Colocaram-se $2,5 \mathrm{~mL}$ desse extrato aquoso em tubos de vidro de $25 \mathrm{~mL}$, com tampa rosqueada, para efetuar a hidrólise ácida em meio de HCI $1 \mathrm{~N}$, em estufa, a $110^{\circ} \mathrm{C}$, durante três horas (Sodek \& Wilson, 1971). Finalmente, o extrato aquoso II, hidrolisado e não hidrolisado, foi evaporado a vácuo, a $45^{\circ} \mathrm{C}$, até a secura, e os resíduos foram dissolvidos em $2 \mathrm{~mL}$ de tampão de citrato de sódio $0,2 \mathrm{~N}, \mathrm{pH} 2,2$ contendo norleucina $\left(0,5.10^{-3} \mathrm{mmoles} / \mathrm{mL}\right)$ como padrão interno, filtrados em papel de filtro $\mathrm{W} \mathrm{no} 1 \mathrm{e}$ armazenados em congelador a $-10^{\circ} \mathrm{C}$, para as determinações posteriores.

A quantificação do $\mathrm{N}$-total e do $\mathrm{N}$-solúvel envolveu, inicialmente, uma digestão sulfo-salicílica (McClure \& Israel, 1979), sendo a mistura catalisadora formada por $\mathrm{Na}_{2} \mathrm{SO}_{4}$ anidro, $\mathrm{CuSO}_{4} .5 \mathrm{H}_{2} \mathrm{O}$ e $\mathrm{Se}$ $(100: 1: 0,8)$. Em seguida, determinou-se o N-total pela reação do fenol alcalino, segundo Cataldo et al. (1974). O N-nítrico foi avaliado pelo método da nitração do ácido salicílico, conforme descrição de Cataldo et al. (1975). A avaliação do $\mathrm{N}$-insolúvel foi obtida por diferença entre os teores de $\mathrm{N}$-total e $\mathrm{N}$-solúvel. O N-amoniacal e o $\mathrm{N}$-aminoácido foram dosados mediante cromatografia de troca iônica, conforme descrito por Spackman et al. (1958), com a utilização de um analisador automático de aminoácidos Beckman, modelo 121. Utilizou-se como solução-padrão uma mistura sintética que continha 0,5.10-3 mmoles $/ \mathrm{mL}$, de 17 aminoácidos normalmente presentes em hidrolisados protéicos e amônia, à qual se adicionou norleucina, na mesma concentração, como padrão interno.

Os resultados dos teores de $\mathrm{N}$-total, $\mathrm{N}$-insolúvel, N-solúvel, N-nítrico, açúcares solúveis totais e açúcares redutores foram comparados pela análise de variância e as médias pelo teste de Tukey, a 5\% de probabilidade.

\section{RESULTADOS E DISCUSSÃO}

$\mathrm{Na}$ ausência do $\mathrm{Al}$, os teores de $\mathrm{N}$-total e $\mathrm{N}$-insolúvel da parte aérea (Tabela 1) e do sistema radicular (Tabela 2) não foram influenciados pela fonte de $\mathrm{N}$ em ambas as espécies. Contudo, houve tendência de diminuição dos teores de $\mathrm{N}$-insolúvel na parte aérea de $S$. guianensis quando o $\mathrm{N}$ foi 
suprido pela fonte amoniacal, em relação à fonte nítrica. Expressando-se esses resultados em porcentagem do $\mathrm{N}$-total, encontraram-se os valores de $91 \%$ e $78 \%$ em relação a $S$. guianensis suprido com as fontes nítrica e amoniacal, respectivamente. Referente a $S$. macrocephala, esses valores ficaram em torno de $92 \%$, independentemente da fonte de $\mathrm{N}$. Em contraste, os teores de $\mathrm{N}$-solúvel aumentaram com a nutrição amoniacal na parte aérea (Tabela 1) de $S$. guianensis e no sistema radicular (Tabela 2) de S. macrocephala, ao passo que os teores de $\mathrm{N}$-amoniacal e $\mathrm{N}$-aminoácidos aumentaram na parte aérea (Tabela 1), no sistema radicular (Tabela 2) de $S$. guianensis, e no sistema radicular (Tabela 2) de S. macrocephala. Simultaneamente, a nutrição amoniacal causou o aparecimento de sintomas visíveis de toxidez de amônio apenas em S. guianensis, que aos 12 dias de tratamento caracterizaram-se pela clorose e por lesões necróticas das folhas, do ápice em direção à base, e por queda das folhas inferiores. Sintomas similares foram observados por Barker et al. (1966) em feijão, por Cordeiro (1981) em S. guianensis, por Dirr (1975) em viburno, e por Maynard \& Barker (1969) em feijão, pepino e ervilha. Esses resultados sugerem que $S$. macrocephala, comparativamente a
S. guianensis, teria maior capacidade para reter e assimilar o amônio no sistema radicular, prevenindo o acúmulo desse íon na parte aérea, onde ele é tóxico em concentrações relativamente baixas (Hageman \& Below, 1990), podendo desacoplar a fotofosforilação (Trebst et al., 1960), inibir a síntese de clorofila (Bogorad, 1976) e promover a degradação de cloroplastídios (Puritch \& Barker, 1967) e de proteínas (Barker et al., 1966). Assim, os teores relativamente elevados de amônio e de aminoácidos encontrados na parte aérea de S. guianensis, durante a nutrição amoniacal, sugerem decréscimos na síntese ou aumentos na degradação de proteínas, visto que os teores de $\mathrm{N}$-insolúvel tenderam a diminuir com a fonte amoniacal. Deve-se salientar que pequenas variações nas concentrações de $\mathrm{N}$-insolúvel podem causar acentuada mudança nos teores das frações solúveis.

Minucioso estudo sobre a toxidez de amônio foi realizado por Barker et al. (1966) com plantas de feijão, utilizando ${ }^{15} \mathrm{~N}$-amoniacal. Eles observaram que o incremento de amônio e de aminoácidos na parte aérea das plantas, após cinco dias de exposição ao amônio (três dias depois da exposição ao ${ }^{15} \mathrm{~N}$-amoniacal), sem controle da acidez do meio,

TABELA 1. Teores de $\mathrm{N}$-total, $\mathrm{N}$-insolúvel, $\mathrm{N}$-solúvel, $\mathrm{N}$-nítrico, $\mathbf{N}$-aminoácidos, $\mathbf{N}$-amoniacal e açúcares solúveis totais (Aç. sol. totais) e açúcares redutores (Aç. redutores) da parte aérea de Stylosanthes guianensis e $S$. macrocephala, com duas fontes de nitrogênio $\left(\mathrm{N}-\mathrm{NO}_{3}^{-}\right.$e $\left.\mathrm{N}-\mathrm{NH}_{4}^{+}\right)$e dois níveis de $\mathrm{Al}$ (0 e 9 ppm) $)^{1}$.

\begin{tabular}{|c|c|c|c|c|c|c|c|c|}
\hline \multirow[t]{3}{*}{ Determinações } & \multicolumn{4}{|c|}{ S. guianensis } & \multicolumn{4}{|c|}{ S. macrocephala } \\
\hline & \multicolumn{2}{|c|}{$\mathrm{N}-\mathrm{NO}_{3}^{-}$} & \multicolumn{2}{|c|}{$\mathrm{N}-\mathrm{NH}_{4}^{+}$} & \multicolumn{2}{|c|}{$\mathrm{N}-\mathrm{NO}_{3}^{-}$} & \multicolumn{2}{|c|}{$\mathrm{N}-\mathrm{NH}_{4}^{+}$} \\
\hline & 0 & 9 & 0 & 9 & 0 & 9 & 0 & 9 \\
\hline & & --. & ------- & $-(\mathrm{mg} / \mathrm{g}$ & éria sec & ------- n n & ---------- & -------- \\
\hline N-total & $48,9 \mathrm{a}$ & $47,3 \mathrm{a}$ & $48,5 \mathrm{a}$ & $46,1 \mathrm{a}$ & $39,8 b$ & $51,9 \mathrm{a}$ & $46,3 \mathrm{ab}$ & $47,4 a$ \\
\hline $\mathrm{N}$-insolúvel & $44,5 \mathrm{a}$ & $42,9 \mathrm{a}$ & $37,8 \mathrm{a}$ & $38,3 \mathrm{a}$ & $36,5 b$ & $46,5 \mathrm{a}$ & $42,6 a b$ & $42,9 \mathrm{ab}$ \\
\hline N-solúvel & $4,4 \mathrm{c}$ & $4,4 \mathrm{c}$ & $10,7 \mathrm{a}$ & $7,8 \mathrm{~b}$ & $3,3 \mathrm{c}$ & $5,4 \mathrm{a}$ & $3,7 b c$ & $4,5 \mathrm{ab}$ \\
\hline N-nítrico & $1,3 \mathrm{a}$ & $1,1 \mathrm{a}$ & - & - & $0,9 b$ & $1,5 \mathrm{a}$ & - & - \\
\hline $\mathrm{N}$-aminoácidos & 1,8 & 2,0 & 7,0 & 4,1 & 0,8 & 2,3 & 1,8 & 2,4 \\
\hline N-amoniacal & 0,2 & 0,3 & 1,3 & 1,0 & 0,3 & 0,4 & 0,4 & 0,3 \\
\hline Aç. sol. totais & $27,6 \mathrm{c}$ & $30,3 c$ & $88,4 a$ & $68,1 b$ & $24,7 \mathrm{a}$ & $23,9 \mathrm{a}$ & $20,9 a$ & $22,4 \mathrm{a}$ \\
\hline Aç. redutores & $9,6 c$ & $10,9 \mathrm{c}$ & $19,8 \mathrm{a}$ & $13,9 b$ & $8,6 \mathrm{a}$ & $6,8 \mathrm{a}$ & $6,6 a$ & $7,5 \mathrm{a}$ \\
\hline
\end{tabular}


derivou, basicamente, da degradação de proteínas. Contudo, pelo menos parte do incremento nas frações do N-solúvel da parte aérea de S. guianensis suprido com a fonte amoniacal deve ter sido decorrente do transporte de amônio e de aminoácidos livres para os ramos, via xilema. Sabe-se que, embora o amônio possa ser assimilado em grande parte nas raízes (Pate \& Wallace, 1964; Weissman, 1972; Beevers \& Hageman, 1980; Atkins \& Beevers, 1990), algumas plantas podem transportá-lo em quantidades consideráveis para a parte aérea (Weissman, 1972). Portanto, os altos níveis de $\mathrm{N}$-amoniacal e de $\mathrm{N}$-aminoácidos da parte aérea de $S$. guianensis suprido com amônio devem ter-se originado tanto da degradação de proteínas quanto do transporte de amônio e de aminoácidos para os ramos.

A introdução do Al na solução de cultivo minimizou os efeitos tóxicos do amônio em S. guianensis, onde os sintomas de toxidez desse íon apresentaram-se menos intensos. Todavia, em S. guianensis submetido à nutrição amoniacal a adição do $\mathrm{Al}$ à solução de cultivo não influenciou os teores de N-total e $\mathrm{N}$-insolúvel (Tabelas 1 e 2). Contudo, expressando os teores de $\mathrm{N}$-insolúvel da parte aérea de $S$. guianensis em porcentagem do
$\mathrm{N}$-total, encontraram-se os valores de $78 \%$ e $83 \%$ na ausência e na presença do Al, respectivamente. Por outro lado, o Al causou decréscimos nos teores de $\mathrm{N}$-solúvel, $\mathrm{N}$-amoniacal e $\mathrm{N}$-aminoácidos na parte aérea de $S$. guianensis (Tabela 1). É possível que essas reduções nas frações do N-solúvel, pela ação do Al, em S. guianensis, estejam associadas a diminuições na degradação de proteínas na parte aérea dessas plantas. Já em $S$. macrocephala suprido com amônio, o Al praticamente não influenciou a composição nitrogenada na parte aérea (Tabela 1), embora tenha ocorrido tendências de aumentos nos teores de N-total e N-insolúvel no sistema radicular (Tabela 2).

Alguns pesquisadores (Kotze et al., 1977; Cordeiro, 1981) têm verificado que os efeitos tóxicos do Al manifestam-se apenas quando o $\mathrm{N}$ é suprido pela fonte nítrica. Assim, ao fim do período de tratamento, que se prolongou por 12 dias, observou-se amarelecimento do ápice dos folíolos apenas de $S$. guianensis suprido com nitrato, na presença do Al. Sintomas semelhantes foram notados por Gates \& Wilson (1974), com mínima intensidade em plantas com mais altos teores de $\mathrm{Ne}$ P. Concomitantemente, as raízes de S. guianensis suprido com nitrato na presença do $\mathrm{Al}$, apresentaram-se

TABELA 2. Teores de $\mathbf{N}$-total, $\mathbf{N}$-insolúvel, $\mathbf{N}$-solúvel, $\mathbf{N}$-nítrico, $\mathbf{N}$-aminoácidos, $\mathbf{N}$-amoniacal e açúcares solúveis totais (Aç. sol. totais) e açúcares redutores (Aç. redutores) do sistema radicular de Stylosanthes guianensis e $S$. macrocephala, com duas fontes de nitrogênio $\left(\mathrm{N}_{-} \mathrm{NO}_{3}^{-}\right.$e $\left.\mathrm{N}-\mathrm{NH}_{4}^{+}\right)$e dois níveis de Al (0 e 9 ppm) 1 .

\begin{tabular}{|c|c|c|c|c|c|c|c|c|}
\hline \multirow[t]{3}{*}{ Determinações } & \multicolumn{4}{|c|}{ S. guianensis } & \multicolumn{4}{|c|}{ S. macrocephala } \\
\hline & \multicolumn{2}{|c|}{$\mathrm{N}-\mathrm{NO}_{3}^{-}$} & \multicolumn{2}{|c|}{$\mathrm{N}-\mathrm{NH}_{4}^{+}$} & \multicolumn{2}{|c|}{$\mathrm{N}-\mathrm{NO}_{3}^{-}$} & \multicolumn{2}{|c|}{$\mathrm{N}-\mathrm{NH}_{4}^{+}$} \\
\hline & 0 & 9 & 0 & 9 & 0 & 9 & 0 & 9 \\
\hline & -------- & - & ------ & $\mathrm{mg} / \mathrm{g} \mathrm{m}$ & a seca) & & - & \\
\hline N-total & $39,7 \mathrm{a}$ & $36,1 \mathrm{a}$ & $37,8 \mathrm{a}$ & $35,8 \mathrm{a}$ & $39,9 b$ & $49,3 \mathrm{a}$ & $42,2 \mathrm{ab}$ & $46,0 \mathrm{ab}$ \\
\hline $\mathrm{N}$-insolúvel & $30,6 a$ & $29,8 \mathrm{a}$ & $29,1 \mathrm{a}$ & $26,7 \mathrm{a}$ & $29,3 \mathrm{a}$ & $34,5 \mathrm{a}$ & $28,5 \mathrm{a}$ & $32,1 \mathrm{a}$ \\
\hline $\mathrm{N}$-solúvel & $9,1 \mathrm{a}$ & $6,3 \mathrm{a}$ & $8,7 \mathrm{a}$ & $9,1 \mathrm{a}$ & $10,6 b$ & $14,8 \mathrm{a}$ & $13,7 \mathrm{a}$ & $13,9 \mathrm{a}$ \\
\hline N-nítrico & $3,1 \mathrm{a}$ & $2,2 \mathrm{a}$ & - & - & $2,0 \mathrm{~b}$ & $5,5 \mathrm{a}$ & - & - \\
\hline $\mathrm{N}$-aminoácidos & 2,8 & 2,1 & 5,5 & 6,2 & 4,3 & 6,9 & 11,0 & 11,2 \\
\hline N-amoniacal & 0,5 & 0,5 & 0,9 & 0,9 & 0,9 & 0,6 & 1,4 & 1,0 \\
\hline Aç. sol. totais & $34,0 \mathrm{a}$ & $30,1 \mathrm{a}$ & $19,7 \mathrm{~b}$ & $19,1 \mathrm{~b}$ & $60,2 a$ & $39,5 \mathrm{c}$ & $50,5 b$ & $38,5 \mathrm{c}$ \\
\hline Aç. redutores & $7,1 \mathrm{a}$ & $4,6 a b$ & $4,2 \mathrm{ab}$ & $1,9 b$ & $14,0 \mathrm{a}$ & $3,4 b$ & $12,8 \mathrm{a}$ & $4,0 \mathrm{~b}$ \\
\hline
\end{tabular}


ligeiramente grossas, com pontos escuros nas extremidades, conforme caracterizados anteriormente por outros pesquisadores (Mosquim, 1978; Cordeiro, 1981), o que sugere inibição do Al sobre o alongamento e divisão celular (Kochian, 1995). Todavia, o Al não alterou os teores de $\mathrm{N}$-total, $\mathrm{N}$-insolúvel, $\mathrm{N}$ solúvel, $\mathrm{N}$-amoniacal, $\mathrm{N}$-aminoácidos e $\mathrm{N}$-nítrico de S. guianensis suprido com nitrato (Tabelas 1 e 2). Em contraste, o Al aumentou os teores desses compostos nitrogenados em $S$. macrocephala suprido com nitrato, exceto os referentes ao $\mathrm{N}$-amoniacal, que tenderam a diminuir no sistema radicular. Esses resultados são confirmados pelas observações de Mosquim (1978) de que o Al aumentou os teores de aminoácidos e de proteínas de $S$. humilis, espécie medianamente resistente ao elemento. Provavelmente, o aumento do nível de aminoácidos, em algumas espécies, está associado à síntese de proteínas específicas nas células, que confeririam ao genótipo maior resistência ao Al (Klimashevskii et al., 1970).

Esses incrementos no conteúdo nitrogenado de S. macrocephala suprido com nitrato, na presença do Al devem estar associados aos estímulos do Al às atividades da redutase do nitrato e da sintetase da glutamina (Gonçalves, 1983) e à absorção de nitrato, conforme verificado por Cordeiro (1981) e Gonçalves (1983). Esses autores demonstraram que o elemento não influiu na absorção de nitrato por S. guianensis, absorção que foi estimulada em S. macrocephala. Considerando que a redutase do nitrato seja induzida pelo seu substrato (Beevers \& Hageman, 1980; Oaks \& Hirel, 1985; Wallace, 1987), pode-se concluir que a assimilação do nitrato está associada com a absorção desse ânion em S. macrocephala (Gonçalves, 1983), podendo influenciar o conteúdo de N-nítrico, N-aminoácidos, $\mathrm{N}$-solúvel, N-insolúvel e N-total (Tabelas 1 e 2).

Com relação aos carboidratos, verificou-se que a fonte amoniacal, comparada à nítrica, reduziu os teores de açúcares solúveis totais no sistema radicular (Tabela 2) das duas espécies. Sabe-se que os carboidratos são indispensáveis como fonte de esqueletos carbônicos, e, em alguns casos, como substrato respiratório para o suprimento da energia necessária à assimilação do amônio (Givan, 1979;
Miflin \& Lea, 1980; Oaks \& Yamaya, 1990; Stulen 1990). Desse modo, decréscimos nos teores de açúcares solúveis totais no sistema radicular (Tabela 2) sugerem mais rápida assimilação do amônio, em relação ao nitrato. Portanto, os decréscimos nos teores de açúcares solúveis totais no sistema radicular das duas espécies, em decorrência da nutrição amoniacal, devem estar relacionados com o incremento da síntese de compostos orgânicos nitrogenados durante os processos de desintoxicação dos íons amoniacais, conforme observado por Syrett (1956a, 1956b) em algas unicelulares.

Em S. guianensis suprido com amônio, os teores de açúcares solúveis totais e redutores da parte aérea (Tabela 1) aumentaram muito, em relação à fonte nítrica, à semelhança dos resultados obtidos por Kirkby (1968) em plantas de mostarda-branca. Esses elevados teores de açúcares na parte aérea sugerem hidrólise de carboidratos de reserva e distúrbios na partição de fotoassimilados entre a parte aérea e o sistema radicular.

Em presença do $\mathrm{Al}$, os teores de açúcares solúveis totais e redutores diminuíram na parte aérea de $S$. guianensis submetido à nutrição amoniacal, embora esses valores se mantivessem ainda elevados em relação à fonte nítrica. Por outro lado, em $S$. macrocephala suprido com amônio o Al causou decréscimos nas concentrações de açúcares solúveis totais e redutores no sistema radicular (Tabela 2). Concomitantemente, ocorreu apenas ligeiro aumento no teor de $\mathrm{N}$-aminoácidos na parte aérea (Tabela 1). Assim, não se pode afirmar que essa redução nos teores de açúcares seja conseqüência apenas da sua utilização na síntese de compostos orgânicos nitrogenados, pois pode ter ocorrido também estímulo à atividade da sintetase do amido. No entanto, quando a fonte de $\mathrm{N}$ foi o nitrato, os decréscimos nos teores de açúcares solúveis totais e redutores no sistema radicular de $S$. macrocephala foram seguidos de aumentos nas concentrações de N-total, N-insolúvel, N-solúvel, $\mathrm{N}$-nítrico e $\mathrm{N}$-aminoácidos na parte aérea (Tabela 1) e nas raízes (Tabela 2), o que indica incremento na assimilação do $\mathrm{N}$. 


\section{CONCLUSÕES}

1. Stylosanthes macrocephala, comparativamente a $S$. guianensis, possui maior capacidade para reter e assimilar o amônio no sistema radicular, prevenindo o acúmulo desse cátion na parte aérea.

2. A adição do Al na solução nutritiva alivia parcialmente a toxidez de amônio ocorrida somente em $S$. guianensis.

3. Os sintomas de toxidez de Al manifestam-se apenas em $S$. guianensis suprido com a fonte nítrica; em S. macrocephala, nessas condições, ocorrem incrementos nos teores de compostos nitrogenados.

\section{AGRADECIMENTOS}

À Universidade Federal de Viçosa e à Universidade Federal do Espírito Santo, pela oportunidade oferecida para a realização deste trabalho; ao Conselho Nacional de Desenvolvimento Científico e Tecnológico, pelo financiamento parcial do projeto.

\section{REFERÊNCIAS}

ATKINS, C.; BEEVERS, L. Synthesis, transport and utilization of translocated solutes of nitrogen. In: ABROL, Y.P. (Ed.). Nitrogen in higher plants. Taunton : Research Studies, 1990. p.223-295.

BARKER, A.V.; VOLK, R.J.; JACKSON, W.A. Root environment acidity as a regulatory factor in ammonium assimilation by the bean plant. Plant Physiology, v.41, n.7, p.1193-1199, 1966.

BEEVERS, L.; HAGEMAN, R.H. Nitrate and nitrite reduction. In: MIFLIN, B.J. (Ed.). The biochemistry plants. New York : Academic, 1980. v.5, p.115168.

BOGORAD, L. Chlorophyll biosynthesis. In: GOODWIN, T.W. (Ed.). Chemistry and biochemistry of plant pigments. New York : Academic, 1976. p.64-148.

CATALDO, D.A.; HAROON, M.; SCHRADER, L.E.; YOUNGS, V.L. Rapid colorimetric determination of nitrate in plant tissue by nitration of salicylic acid. Communications in Soil Science and Plant Analysis, v.6, n.1, p.71-80, 1975.
CATALDO, D.A.; SCHRADER, L.E.; YOUNGS, V.L. Analysis by digestion and colorimetric assay of total nitrogen in plant tissues high in nitrate. Crop Science, v.14, n.6, p.854-856, 1974.

CORDEIRO, A.T. Efeito de níveis de nitrato, amônio e Al sobre o crescimento e sobre a absorção de fósforo e de nitrogênio em Stylosanthes guianensis e Stylosanthes macrocephala. Viçosa : UFV, 1981. 53p. Tese de Mestrado.

DIRR, M.A. Effect of nitrogen form and $\mathrm{pH}$ on growth, $\mathrm{NO}_{3}^{-}-\mathrm{N}, \mathrm{NH}_{4}^{+}-\mathrm{N}$ and total $\mathrm{N}$ content of containergrown doublefile viburnum. Journal of the American Society for Horticultural Science, v.100, n.3, p.216-218, 1975.

DIRR, M.A. Nitrogen form and growth and nitrate reductase activity of the cranberry. HortScience, v.9, n.4, p.347-348, 1974.

FOY, C.D. Effects of aluminum on plant growth. In: CARSON, E.W. (Ed.). The plant root and its environment. Charlottes Ville : University Press of Virginia, 1974. p.601-641.

FOY, C.D.; CHANEY, R.L.; WHITE, M.C. The physiology of metal toxicity in plants. Annual Review of Plant Physiology, v.29, p.511-566, 1978.

GATES, C.T.; WILSON, J.R. The interaction of nitrogen and phosphorus on the growth, nutrient status and nodulation of Stylosanthes humilis H. B. K. (Townsville Stylo ). Plant and Soil, v.41, n.2, p.325-333, 1974.

GIGON, A.; RORISON, I.H. The response of some ecologically distinct plant species to nitrate and to ammonium nitrogen. Journal of Ecology, v.60, n.1, p.93-102, 1972.

GIVAN, C.V. Review: metabolic detoxification of ammonia in tissues of higher plants. Phytochemistry, v.18, n.3, p.375-382, 1979.

GONÇALVES, M.C. Influência do Al, nitrato e amônio na absorção e na assimilação do nitrogênio, em Stylosanthes guianensis e $S$. macrocephala. Viçosa : UFV, 1983. 38p. Tese de Mestrado.

GREIDANUS, T.; PETERSON, L.A.; SCHRADER, L.E.; DANA, M.N. Essentiality of ammonium for cranberry nutrition. Journal of the American Society for Horticultural Science, v.97, n.2, p.272-277, 1972. 
HAGEMAN, R.H.; BELOW, F.E. Role of nitrogen metabolism in crop productivity. In: ABROL, Y.P. (Ed.). Nitrogen in higher plants. Taunton : Research Studies, 1990. p.313-334.

KIRKBY, E.A. Influence of ammonium and nitrate nutrition on the cation - anion balance and nitrogen and carbohydrate metabolism of white mustard plants grown in dilute nutrient solutions. Soil Science, v.105, p.3, p.133-141, 1968.

KLIMASHEVSKII, É.L.; MARKOVA, Y.A.; SEREGINA, M.L.; GRODZINSKII, D.M.; KOZARENKO, T.D. Specifics of the physiological activity of pea plants in connection with unequal resistance of different varieties to mobile aluminum. Soviet Plant Physiology, v.17, n.3, p.372-378, 1970.

KOCHIAN, L.V. Cellular Mechanisms of aluminum toxicity and resistance in plants. Annual Review of Plant Physiology and Plant Molecular Biology, v.46, p.237-260, 1995.

KOTZE, W.A.G.; SHEAR, C.B.; FAUST, M. Effect of nitrogen source and aluminum in nutrient solution on the growth and mineral nutrition of apple and peach seedlings. Journal of the American Society for Horticultural Science, v.102, n.3, p.279-282, 1977.

MARSCHNER, H. Mineral nutrition of higher plants London : Academic, 1986. 674p.

MAYNARD, D.N.; BARKER, A.V. Studies on the tolerance of plants to ammonium nutrition. Journal of the American Society for Horticultural Science, v.94, n.3, p.235-239, 1969.

McCLURE, P.R.; ISRAEL, D.W. Transport of nitrogen in the xylem of soybean plants. Plant Physiology, v.64, n.3, p.411-416, 1979.

MEDAPPA, K.C.; DANA, M.N. Tolerance of cranberry plants to manganese, iron and aluminum. Journal of the American Society for Horticultural Science, v.95, n.1, p.107-110, 1970 .

MIFLIN, B.J.; LEA, P.J. Ammonia assimilation. In MIFLIN, B.J. (Ed.). The biochemistry of plants New York : Academic, 1980. p.169-202.

MOSQUIM, P.R. Influência do Al sobre o crescimento e o metabolismo em plantas de Stylosanthes humilis H. B. K. Viçosa : UFV, 1978. 29p. Tese de Mestrado.

OAKS, A.; HIREL, B. Nitrogen metabolism in roots. Annual Review of Plant Physiology, v.36, p.345-365, 1985.

OAKS, A.; YAMAYA, T. Nitrogen assimilation in leaves and roots - a role for glutamate dehydrogenase. In:
ABROL, Y.P. (Ed.). Nitrogen in higher plants. Taunton : Research Studies, 1990. p.181-194.

PATE, J.S.; WALLACE, W. Movement of assimilated nitrogen from the root system of field pea (Pisum arvense L.). Annals of Botany, v.28, n.109, p.83-99, 1964

PURITCH, G.S.; BARKER, A.V. Structure and function of tomato leaf chloroplasts during ammonium toxicity. Plant Physiology, v.42, n.7, p.1229-1238, 1967.

SODEK, L.; WILSON, C.M. Amino acid composition of proteins isolated from normal, opaque-2, and floury-2 corn endosperms by a modified Osborne procedure. Journal of Agricultural and Food Chemistry, v.19, n.6, p.1144-1150, 1971.

SPACKMAN, D.H.; STEIN, W.H.; MOORE, S Automatic recording apparatus for use in the chromatography of amino acids. Analytical Chemistry, v.30, n.7, p.1190-1206, 1958.

STULEN, I. Interactions between carbon anal nitrogen metabolism in relation to plant growth anal productivity. In: ABROL, Y.P. (Ed.). Nitrogen in higher plants. Taunton : Research Studies, 1990. p. 297-312.

SYRETT, P.J. The assimilation of ammonia by nitrogenstarved cells of Chlorella vulgaris: II. The assimilation of large quantities of nitrogen. Physiologia Plantarum, v.9, n.1, p.19-27, 1956a.

SYRETT, P.J. The assimilation of ammonia and nitrate by nitrogen- starved cells of Chlorella vulgaris. III. Differences of metabolism dependent on the nature of nitrogen source. Physiologia Plantarum, v.9, n.1, p.28-37, 1956b.

TREBST, A.V.; LOSADA, M.; ARNON, D.I. Photosynthesis by isolated chloroplasts: XII. Inhibitors of $\mathrm{CO}_{2}$ assimilation in a reconstituted chloroplast system. Journal of Biological Chemistry, v.235, n.3, p.840-844, 1960.

WALLACE, W. Regulation of nitrate utilization on higher plants. In: ULLRICH, W.R.; APARICIO, P.J.; SYRETT, P.J. (Eds.). Inorganic nitrogen metabolism. Berlin : Springer-Verlag, 1987. p.223230 .

WANG, D.; WAYGOOD, E.R. Carbon metabolism of C ${ }^{14}$ labeled amino acids in wheat leaves: I. A pathway of glyoxylate-serine metabolism. Plant Physiology, v.37, n.6, p.826-832, 1962.

WEISSMAN, G.S. Influence of ammonium and nitrate nutrition on enzymatic activity in soybean and sunflower. Plant Physiology, v.49, n.2, p.138-141, 1972. 